\title{
Factors Associated with Lamina Cribrosa Displacement After Trabeculectomy Measured by Optical Coherence Tomography in Advanced Primary Open Angle Glaucoma
}

Hamed Esfandiari, ${ }^{1,2}$ Ali Efatizadeh, ${ }^{1}$ Azadeh Doozandeh, ${ }^{1}$ Mehdi Yaseri, ${ }^{3}$ Nils A. Loewen ${ }^{2}$

\footnotetext{
${ }^{1}$ Ophthalmic Research Center, Shahid Beheshti University of Medical Sciences, Tehran, Iran ${ }^{2}$ Department of Ophthalmology, School of Medicine, University of Pittsburgh, Pittsburgh, Pennsylvania, United States

${ }^{3}$ Department of Epidemiology and Biostatistics, School of Public Health, Tehran University of Medical Sciences, Tehran, Iran
}

Correspondence: Nils A. Loewen, MD, PhD

University of Pittsburgh, School of Medicine

Department of Ophthalmology

203 Lothrop St.

Pittsburgh, PA 15213

Email: loewen.nils@gmail.com or Loewenna@upmc.edu

Phone: 412-944-2554 Fax: 412-647-5119 


\begin{abstract}
Purpose: To investigate the relationship of lamina cribrosa displacement to corneal biomechanical properties and visual function after mitomycin C-augmented trabeculectomy.
\end{abstract}

Method: Eighty-one primary open angle eyes were imaged before and after trabeculectomy using an enhanced depth spectral-domain optical coherence tomography (SDOCT). Corneal biomechanical properties were measured with the Ocular Response Analyser before the surgery. The anterior lamina cribrosa (LC) was marked at several points in each of six radial scans to evaluate LC displacement in response to Intraocular pressure (IOP) reduction. A Humphrey visual field test (HVF) was performed before the surgery as well as three and six months postoperatively.

Results: Factors associated with a deeper baseline anterior lamina cribrosa depth (ALD) were cup-disc ratio $(P=0.04)$, baseline IOP $(P=0.01)$, corneal hysteresis $(P=0.001)$, and corneal resistance factor $(P=$ 0.001). After the surgery, the position of LC became more anterior (negative), posterior (positive) or remained unchanged. The mean LC displacement was $-42 \mu \mathrm{m}(\mathrm{P}=0.001)$ and was positively correlated with the magnitude of IOP reduction (regression coefficient: $0.251, P=0.02$ ), and negatively correlated with age (regression coefficient: $-0.224, \mathrm{P}=0.04$ ) as well as baseline cup-disk ratio (Regression coefficient: $-0.212, P=0.05$ ) Eyes with a larger negative LC displacement were more likely to experience an HVF improvement of more than $3 \mathrm{~dB}$ gain in mean deviation $(P=0.002)$.

Conclusion: A lower SDOCT cup-disc ratio, younger age, and a larger IOP reduction were correlated with a larger negative LC displacement and improving HVF. Corneal biomechanics did not predict LC displacement.

Keywords: glaucoma, lamina cribrosa, optic nerve head, optical coherence tomography, corneal hysteresis, visual field, trabeculectomy 


\section{Introduction}

Loss of visual function in glaucoma is secondary to axonal ganglion cell damage ${ }^{1}$ initiated in and near the lamina cribrosa (LC). ${ }^{2}$ Although a causative link between high intraocular pressure and optic nerve damage is well-established in glaucoma, the exact mechanism remains only partially understood. ${ }^{3}$ High IOP and IOP fluctuations cause biomechanical stress and strain that compress, dislocate, stretch and shear the LC. ${ }^{4}$ This leads to a mechanical failure of the load-bearing connective tissues of the $\mathrm{ONH}$, to damage of nearby axons and compromise of the optic nerve head (ONH) blood supply. ${ }^{2,4-6}$ The mechanical failure is followed by a posterior bowing and compaction of the LC. ${ }^{4,7}$ Patient-specific properties of the LC may explain why some patients are more likely to develop glaucoma damage despite a similar IOP. The extracellular matrix that adds to the biomechanical properties of the LC is composed of collagens, elastins, and proteoglycans. ${ }^{8,9}$ Collagen fibers primarily resist tensile forces and determine tissue elasticity while proteoglycans resist compressive forces and confer viscosity. ${ }^{10}$

The proteoglycans are similar in the cornea and LC despite different collagen types in these tissues. ${ }^{11}$ Although an in vivo assessment of the biomechanical properties of the LC is not directly possible, the cornea can be readily analyzed with an ocular response analyzer (ORA, Reichert Instruments, Depew, NY). An examination of the biomechanical features of the cornea might serve as a substitute for the LC. ${ }^{12,13}$ The ORA ${ }^{14}$ uses a metered air jet to displace the cornea and determine its hysteresis. This variable can be described as the delay between a cause and an effect or in this case, the difference between the pressure at which the cornea bends posteriorly during an airjetapplanation and the pressure at which it moves anteriorly again. A larger $\mathrm{CH}$ can be interpreted as increased viscoelastic damping of stress-strain forces.

While the importance of the LC in glaucoma pathogenesis has been shown in mathematical models, and in ex vivo and in vivo studies, ${ }^{1,5,15,16}$ high resolution in vivo assessment has only become available recently. ${ }^{17,18}$ The association between corneal and ONH biomechanical properties had been explored in several studies in an attempt to propose easily measurable $\mathrm{CH}$ as a biomarker for LC biomechanical behaviour. ${ }^{2,12,13,19}$

The results remained contradictory: while some studies suggested a higher $\mathrm{CH}$ is associated with a greater anterior lamina cribrosa depth change (ALDC), ${ }^{12,13}$ others observed an association with a low $\mathrm{CH}$ and thin corneal thickness. ${ }^{2,20} \mathrm{~A}$ limitation of these studies was that the ALDC was measured in healthy eyes following an increase ${ }^{13}$ in IOP or only a modest IOP reduction in glaucomatous eyes after initiating medical treatment. ${ }^{12}$ The biomechanical properties of the LC in healthy eyes are different from eyes exposed to the chronic stress-strain deformation seen in glaucoma that leads to optic nerve 
head remodelling. ${ }^{21,22}$ In addition, the IOP reduction achieved by glaucoma eye drops only alters the stress (force per unit area) and strain (proportional deformation) within a limited range ${ }^{12}$ given that the Young's modulus of the $\mathrm{ONH}$ is higher than other ocular tissues. ${ }^{23}$

In this study, we evaluated the relationship of biomechanical cornea properties to $\mathrm{ONH}$ parameters in eyes undergoing a trabeculectomy. We hypothesized that a higher $\mathrm{CH}$ would predict a larger ALDC.

\section{Methods}

\section{Study design}

The protocol of this study was approved by the institutional review board of the Shahid Beheshti University of Medical Science (protocol number: IR.SBMU.ORC.REC.95267) and adhered to the tenets of the Declaration of Helsinki. Informed written consent was obtained from each participant. Patients with uncontrolled primary open angle glaucoma (POAG) on maximum medical treatment and age above 25 years were enrolled in this study. The exclusion criteria consisted of a history of prior ocular surgery, need for a combined cataract procedure, ocular or systemic comorbidities that could affect the corneal biomechanics measurement including corneal opacities and dystrophies, keratectasia, connective tissue disease and uncontrolled diabetes, and pregnancy or nursing. Only one eye of each eligible patient was included chosen randomly by coin flip.

\section{Clinical data acquisition}

At baseline, all patients underwent a comprehensive ophthalmic examination including best-corrected visual acuity (BCVA), slit lamp examination, Goldmann applanation tonometry, gonioscopy, and fundus examination. Patients had at least two reliable (less than $33 \%$ fixation losses, false negatives, and false positives) on 24-2 standard automated perimetry visual fields (Humphrey visual field analyzer (HVF); model 750; Carl Zeiss Meditec, Dublin, California, USA) before the operation. We collected the mean deviation (MD) from the HVF. To detect any changes in visual function after surgery, we defined a $3 \mathrm{~dB}$ change in mean deviation (MD) as the cutoff point for detecting a change in the visual field. ${ }^{24}$ Baseline axial length and central corneal thickness were measured with a modified Michelson interferometer that uses infrared laser light (IOLMaster, Carl Zeiss Meditec, Dublin, California, USA).

Before the surgery, corneal biomechanical properties including $\mathrm{CH}$ and corneal resistance factor (CRF) were obtained by ORA. Three measurements were obtained for each eye, and the average of 
these measurements was considered for final analysis. Measurements with a waveform score above 5 were included.

Spectral domain optical coherence tomography (SDOCT, Spectralis; Heidelberg Engineering, Heidelberg, Germany) measurements were performed after dilation with $1 \%$ tropicamide, using an enhanced depth mode by the same operator. The single line scan width produced by the Spectralis OCT is $8.9 \mathrm{~mm}$ long including $1024 \mathrm{~A}$-scans per B-scan and $25 \mathrm{~B}$-scan per second. Six high-resolution radial scans were centered on the $\mathrm{ONH}$. Since the images had the fixed size but different magnification, all the exported images were rescaled to 1:1 pixel using a customized computer program developed in Matlab (R2010a, the MathWorks, Inc., Natick, MA). On each radial scan, Bruch's membrane opening (BMO) was identified and connected by a line as a reference line ${ }^{25}$ and multiple points were marked on this line with an interval of $50 \mu \mathrm{m}$. We applied a subjective LC visibility grading ${ }^{26}$ that describes the anterior LC as "grade 0 " if no part is visible, "grade 1 " if less than $25 \%$ is visible, "grade 2 " for less than $50 \%$, "grade 3" for less than $75 \%$, and "grade 4 " for greater than $75 \%$ is visible. Only scans with LCVG $\geq$ 3 were considered for inclusion. The mean of vertical lines from marked points on the reference line to the anterior surface of the LC was designated as the anterior lamina cribrosa depth (ALD). The difference between the pre- and postsurgical ALD was called LC displacement (ALDC). The prelaminar tissue thickness (PLTT) for each point was defined as the difference between the perpendicular distance from the reference line to the overlapping en face prelaminar tissue surface and anterior lamina cribrosa border. The LC thickness (ALD) was the difference between the perpendicular distance from anterior and posterior LC border at each point.

\section{Surgical technique}

After a peribulbar injection of $2 \mathrm{~mL}$ 2\%lidocaine (Lignidic 2\%, Caspian Tamin Pharmaceutical Co., Rasht, Iran), the cul-de-sacs was irrigated with povidone-iodine and normal saline solution followed by sterile draping and insertion of the lid speculum. $0.1 \mathrm{~mL}$ of mitomycin C 0.01\% (MMC, Mitomycin C Kyowa, Kogyo Company, Tokyo, Japan) was injected into the subtenon space in the superior cul-de-sac and diffusely spread with a blunt spatula over the superior conjunctiva; a Weck-Cel was used to prevent anterior migration of the MMC limiting it to the area covered by the upper lid. The conjunctival peritomy was performed at the superior to superonasal quadrant for 1.5-2 clock hours followed by blunt dissection of Tenon's one minute after MMC injection. The operation field was copiously irrigated with balanced salt solution (BSS). A $3.0 \times 4.0 \mathrm{~mm}$ trapezoidal half-thickness scleral flap was created using a crescent knife followed by lamellar dissection of the scleral flap $1 \mathrm{~mm}$ into clear 
cornea. After fashioning a sideport, the anterior chamber was entered underneath the scleral flap with a keratome, and the incision was squared off with the sideport knife. An anterior tissue block that included clear cornea was removed with a Kelly punch, and a peripheral iridectomy was performed using Vannas scissors. The scleral flap was tied down with two 10-0 nylon releasable sutures, the knots were buried, and the conjunctiva was closed with two 10-0 nylon wing sutures. At the conclusion of surgery, 50mg cefazolin (Cefazolin 500, Exir pharmaceutical, Tehran, Iran) and 2mg of betamethasone (Betazone, Caspian Tamin Pharmaceutical., Rasht, Iran) were given into the inferior fornix.

Postoperatively, patients were seen on a weekly basis for one month and then monthly up to three months. The comprehensive eye exam was performed at each postoperative visit. The EDI-OCT was repeated one month and visual field three and six months after the surgery.

\section{Results}

A total of 100 patients were enrolled in this study and 81 were included. Fourteen were excluded for a low LCVG and five lost to follow-up. All patients were phakic from the beginning to the end of the study. The mean age of study participants was $61.0 \pm 13.3$ years, and $44(54.3 \%)$ of the patients were male $(P=0.901)$. The demographic data are presented in Table 1. The mean preoperative IOP was 22.8 $\pm 5.1 \mathrm{mmHg}$ on $3.1 \pm 0.9$ medications and decreased to $8.6 \pm 2.5 \mathrm{mmHg}$ at the three-month follow-up (Table $2, P<0.001$ ). The baseline visual acuity was $0.5 \pm 0.5 \log M A R$ and decreased to $0.6 \pm 0.5 \log M A R$ at final follow-up $(P<0.001)$ while the HVF MD changed from $-17 \pm 5 d B$ at baseline to $-16 \pm 6 \mathrm{~dB}$ at final follow-up ( $P=0.23)$. Lamina cribrosa thickness ( $L C T)$ and BMO remained unchanged $(P s=0.398$ and 0.234, respectively) but PLTT increased from $47 \pm 12 \mu \mathrm{m}$ at baseline to $52 \pm 12 \mu \mathrm{m}$ ( $p<0.001$ ). Also, ALD decreased from $366 \pm 167 \mu \mathrm{m}$ at baseline to $324 \pm 165 \mu \mathrm{m}$ at the one-month follow-up $(P=<0.001$, Table 2). $\mathrm{CH}$ was correlated with CRF (regression coefficient: $0.918, \mathrm{P}<0.001$ ) as well as baseline HVF mean deviation (regression coefficient: $-0.234, \mathrm{P}=0.041$ ). There was no correlation between $\mathrm{CH}$ and other parameters like the baseline LCT, visual acuity, axial length, changes in IOP, ALDC, and changes in MD.

Parameters associated with a deeper ALD were the cup-disk ratio (regression coefficient: 0.07, $\mathrm{P}=0.04$ ), baseline IOP (regression coefficient: $-.276, \mathrm{P}=0.01$ ), $\mathrm{CH}$ (regression coefficient: $-0.523, \mathrm{P}=$ 0.001 ), and $C R F($ regression coefficient: $-0.509, P=0.001$ ). Scatter plots of relevant covariates significant correlations with ALDC are shown in Figure 1. ALDC was correlated to a younger age (regression coefficient: - $0.224, P=0.04$ ), a larger IOP reduction (regression coefficient: $0.251, P=0.02$ ), a lower baseline cup-disk ratio was correlated with larger LC displacement after the surgery (regression coefficient: $-0.212, \mathrm{P}=0.05)$. 
LC displacement was not associated with sex, corneal biomechanical properties, axial length, corneal thickness, and ALD (Figure 2). Highly hyperopic or myopic eyes were not included in this study. The range was 20 to $25 \mathrm{~mm}$ with a median of $23 \mathrm{~mm}$.

Improvement of visual field was detected in eight (9.8\%) eyes three months following the surgery. MD improvement was correlated with a more extensive ALDC (regression coefficient: $-0.18, \mathrm{P}=$ 0.04, Figure 1). As is presented in Table 3, only ALDC was significantly associated with improvement of the visual field.

\section{Discussion}

Our understanding of glaucomatous optic neuropathy has evolved to include complex biomechanical stress-strain cycle modeling. ${ }^{4}$ The examination of IOP-induced lamina cribrosa movements is receiving increasing interest because they reveal important aspects of biomechanical LC properties ${ }^{4,27}$ and can be measured in vivo. ${ }^{17} \mathrm{CH}$ is associated with the development and progression of glaucoma independent of corneal thickness and intraocular pressure. ${ }^{28}$ The cornea and the sclera contain similar extracellular matrix proteoglycans with comparable viscosities although both are derived from different tissues during ocular development with different collagen fibers. ${ }^{29}$ Eyes with a higher $\mathrm{CH}$ have been observed to experience a larger posterior LC dislocation with increasing IOP, ${ }^{13}$ a larger ALDC following a medical IOP reduction, ${ }^{12}$ and more ONH deformation during experimental IOP elevations. ${ }^{20}$ We hypothesized that a higher $\mathrm{CH}$ would be representative of $\mathrm{LC}$ hysteresis and correlated to a larger post-trabeculectomy ALDC. ${ }^{20}$ Surprisingly, we found this was not the case in our patients. Sigal discussed that the geometry and mechanical properties of the optic nerve head are highly complex and variably influence each other during IOP-induced stresses and strains. ${ }^{30}$ The inclusion of normal participants with healthy loading-unloading cycles and Young's modulus ${ }^{13}$ or a smaller, medical IOP reduction ${ }^{12}$ may explain these differences. A lower $\mathrm{CH}$ has been reported to correlate with glaucoma progression, ${ }^{31}$ possibly due to a reduced viscoelastic dissipation of mechanical forces that could harm axons passing through the LC. On the other hand, larger acute ALDCs have been observed with a large $\mathrm{CH}^{20}$ Glaucoma is a chronic condition that subjects the $\mathrm{LC}$ to the forces of IOP over a long time with an increasing deformation of the LC that becomes permanent. LC creep and tissue remodeling may contribute to the pathogenesis of glaucomatous optic neuropathy. The residual plastic biomechanical deformation affects the LC stress-strain curve and its displacement after IOP reduction, ${ }^{32}$ which also corroborate with less displacement in higher baseline cup-disc ratio as observed in our study. As seen 
before, we observed that patients with a larger IOP reduction had a greater ALDC ${ }^{35-39}$ which inversely correlated with age..$^{35,40,41}$

We saw an MD improvement in eight (9.8\%) patients with a greater ALDC, comparable to previous reports. ${ }^{24,42,43}$ Previous studies showed an improvement in HVF indices between first and second visual fields but not subsequent ones. ${ }^{44,45}$ The extent of LCDC reflects the amount of IOP reduction, ${ }^{35-39}$ but its clinical importance was not clear. Our study suggests that a negative ALDC may remove some of the strain on the $\mathrm{ONH}$.

There are several limitations to our study. The baseline mean deviation and cup-disk ratio were $-17 \pm 5 \mathrm{~dB}$ and $0.81 \pm 0.15$, respectively, consistent with mostly advanced glaucoma. In advanced disease it becomes difficult to delineate the border ${ }^{47}$ but by using several reference line points as well as the LCVG, we only had to discard $15 \%$ of images compared to other studies. ${ }^{12,48,49}$

In summary, age, baseline cup-disc ratio, and magnitude of IOP reduction were correlated to the extent of anterior lamina cribrosa displacement after trabeculectomy but corneal biomechanical properties were not. The visual field mean deviation improved more commonly after a larger anterior lamina cribrosa displacement.

\section{Acknowledgements}

We acknowledge support from NIH CORE Grant P30 EY08098 to the Department of Ophthalmology, from the Eye and Ear Foundation of Pittsburgh, and from an unrestricted grant from Research to Prevent Blindness, New York, NY 


\section{References}

1. Minckler DS, Bunt AH, Johanson GW. Orthograde and retrograde axoplasmic transport during acute ocular hypertension in the monkey. Invest Ophthalmol Vis Sci. 1977;16(5):426-441.

2. Quigley H, Arora K, Idrees S, et al. Biomechanical Responses of Lamina Cribrosa to Intraocular Pressure Change Assessed by Optical Coherence Tomography in Glaucoma Eyes. Invest Ophthalmol Vis Sci. 2017;58(5):2566-2577.

3. Burgoyne CF. A biomechanical paradigm for axonal insult within the optic nerve head in aging and glaucoma. Exp Eye Res. 2011;93(2):120-132.

4. Burgoyne CF, Downs JC, Bellezza AJ, Suh J-KF, Hart RT. The optic nerve head as a biomechanical structure: a new paradigm for understanding the role of IOP-related stress and strain in the pathophysiology of glaucomatous optic nerve head damage. Prog Retin Eye Res. 2005;24(1):39-73.

5. Sigal IA, Grimm JL, Jan N-J, Reid K, Minckler DS, Brown DJ. Eye-specific IOP-induced displacements and deformations of human lamina cribrosa. Invest Ophthalmol Vis Sci. 2014;55(1):1-15.

6. Agoumi Y, Sharpe GP, Hutchison DM, Nicolela MT, Artes PH, Chauhan BC. Laminar and prelaminar tissue displacement during intraocular pressure elevation in glaucoma patients and healthy controls. Ophthalmology. 2011;118(1):52-59.

7. Quigley HA, Green WR. The histology of human glaucoma cupping and optic nerve damage: clinicopathologic correlation in 21 eyes. Ophthalmology. 1979;86(10):1803-1830.

8. Morrison JC, Jerdan JA, L'Hernault NL, Quigley HA. The extracellular matrix composition of the monkey optic nerve head. Invest Ophthalmol Vis Sci. 1988;29(7):1141-1150.

9. Zeimer R. Biomechanical properties of the optic nerve head. Optic nerve in glaucoma. 1995:107-121.

10. Larrabee WF Jr. A finite element model of skin deformation. I. Biomechanics of skin and soft tissue: a review. Laryngoscope. 1986;96(4):399-405.

11. Meek KM, Fullwood NJ. Corneal and scleral collagens-a microscopist's perspective. Micron. 2001;32(3):261-272.

12. Lanzagorta-Aresti A, Perez-Lopez M, Palacios-Pozo E, Davo-Cabrera J. Relationship between corneal hysteresis and lamina cribrosa displacement after medical reduction of intraocular pressure. $\mathrm{Br} J$ Ophthalmol. 2017;101(3):290-294.

13. Fazio MA, Johnstone JK, Smith B, Wang L, Girkin CA. Displacement of the Lamina Cribrosa in Response to Acute Intraocular Pressure Elevation in Normal Individuals of African and European Descent. Invest Ophthalmol Vis Sci. 2016;57(7):3331-3339.

14. Luce DA. Determining in vivo biomechanical properties of the cornea with an ocular response analyzer. J Cataract Refract Surg. 2005;31(1):156-162.

15. Anderson DR, Hendrickson A. Effect of intraocular pressure on rapid axoplasmic transport in monkey optic nerve. Invest Ophthalmol. 1974;13(10):771-783.

16. Sigal IA, Flanagan JG, Tertinegg I, Ethier CR. Finite element modeling of optic nerve head biomechanics. Invest Ophthalmol Vis Sci. 2004;45(12):4378-4387. 
17. Spaide RF, Koizumi H, Pozzoni MC, Pozonni MC. Enhanced depth imaging spectral-domain optical coherence tomography. Am J Ophthalmol. 2008;146(4):496-500.

18. Kim T-W, Kagemann L, Girard MJA, et al. Imaging of the lamina cribrosa in glaucoma: perspectives of pathogenesis and clinical applications. Curr Eye Res. 2013;38(9):903-909.

19. Díez-Álvarez L, Muñoz-Negrete FJ, Casas-Llera P, Oblanca N, de Juan V, Rebolleda G. Relationship between corneal biomechanical properties and optic nerve head changes after deep sclerectomy. Eur J Ophthalmol. 2017;27(5):535-541.

20. Wells AP, Garway-Heath DF, Poostchi A, Wong T, Chan KCY, Sachdev N. Corneal hysteresis but not corneal thickness correlates with optic nerve surface compliance in glaucoma patients. Invest Ophthalmol Vis Sci. 2008;49(8):3262-3268.

21. Bellezza AJ, Rintalan CJ, Thompson HW, Downs JC, Hart RT, Burgoyne CF. Deformation of the lamina cribrosa and anterior scleral canal wall in early experimental glaucoma. Invest Ophthalmol Vis Sci. 2003;44(2):623-637.

22. Downs J, Bellezza AJ, Reynaud JF, Hirons BA, Zhou P, Burgoyne CF. Plastic Deformation of the Lamina Cribrosa Within Digital Three-Dimensional (3D) Reconstructions of Early Glaucomatous Monkey Optic Nerve Heads. Invest Ophthalmol Vis Sci. 2003;44(13):2103-2103.

23. Sigal IA, Flanagan JG, Ethier CR. Factors influencing optic nerve head biomechanics. Invest Ophthalmol Vis Sci. 2005;46(11):4189-4199.

24. Musch DC, Gillespie BW, Palmberg PF, Spaeth G, Niziol LM, Lichter PR. Visual field improvement in the collaborative initial glaucoma treatment study. Am J Ophthalmol. 2014;158(1):96-104.e2.

25. Reis ASC, O'Leary N, Yang H, et al. Influence of clinically invisible, but optical coherence tomography detected, optic disc margin anatomy on neuroretinal rim evaluation. Invest Ophthalmol Vis Sci. 2012;53(4):1852-1860.

26. Girard MJA, Tun TA, Husain R, et al. Lamina cribrosa visibility using optical coherence tomography: comparison of devices and effects of image enhancement techniques. Invest Ophthalmol Vis Sci. 2015;56(2):865-874.

27. Sigal IA, Ethier CR. Biomechanics of the optic nerve head. Exp Eye Res. 2009;88(4):799-807.

28. Susanna CN, Diniz-Filho A, Daga FB, et al. A Prospective Longitudinal Study to Investigate Corneal Hysteresis as a Risk Factor for Predicting Development of Glaucoma. Am J Ophthalmol. January 2018. doi:10.1016/j.ajo.2017.12.018.

29. Coudrillier B, Pijanka J, Jefferys J, et al. Collagen structure and mechanical properties of the human sclera: analysis for the effects of age. J Biomech Eng. 2015;137(4):041006.

30. Sigal IA. Interactions between geometry and mechanical properties on the optic nerve head. Invest Ophthalmol Vis Sci. 2009;50(6):2785-2795.

31. De Moraes CVG, Hill V, Tello C, Liebmann JM, Ritch R. Lower corneal hysteresis is associated with more rapid glaucomatous visual field progression. J Glaucoma. 2012;21(4):209-213.

32. Dal Maso G, DeSimone A, Mora MG, Morini M. A vanishing viscosity approach to quasistatic evolution in plasticity with softening. Arch Ration Mech Anal. 2008;189(3):469-544.

33. Sigal IA, Grimm JL, Jan N-J, Reid K, Minckler DS, Brown DJ. Eye-specific IOP-induced displacements and 
deformations of human lamina cribrosa. Invest Ophthalmol Vis Sci. 2014;55(1):1-15.

34. Sigal IA, Flanagan JG, Tertinegg I, Ethier CR. Predicted extension, compression and shearing of optic nerve head tissues. Exp Eye Res. 2007;85(3):312-322.

35. Lee EJ, Kim T-W, Weinreb RN. Reversal of lamina cribrosa displacement and thickness after trabeculectomy in glaucoma. Ophthalmology. 2012;119(7):1359-1366.

36. Reis ASC, O'Leary N, Stanfield MJ, Shuba LM, Nicolela MT, Chauhan BC. Laminar displacement and prelaminar tissue thickness change after glaucoma surgery imaged with optical coherence tomography. Invest Ophthalmol Vis Sci. 2012;53(9):5819-5826.

37. Park $\mathrm{H}-\mathrm{YL}$, Shin $\mathrm{H}-\mathrm{Y}$, Jung $\mathrm{KI}$, Park $\mathrm{CK}$. Changes in the lamina and prelamina after intraocular pressure reduction in patients with primary open-angle glaucoma and acute primary angle-closure. Invest Ophthalmol Vis Sci. 2014;55(1):233-239.

38. Katz L, Spaeth GL, Cantor LB, Poryzees EM, Steinmann WC. Reversible optic disk cupping and visual field improvement in adults with glaucoma. Am J Ophthalmol. 1989;107(5):485-492.

39. Lesk MR, Spaeth GL, Azuara-Blanco A, et al. Reversal of optic disc cupping after glaucoma surgery analyzed with a scanning laser tomograph1. Ophthalmology. 1999;106(5):1013-1018.

40. Hernandez MR, Luo XX, Andrzejewska W, Neufeld AH. Age-related changes in the extracellular matrix of the human optic nerve head. Am J Ophthalmol. 1989;107(5):476-484.

41. Albon J, Purslow PP, Karwatowski WS, Easty DL. Age related compliance of the lamina cribrosa in human eyes. Br J Ophthalmol. 2000;84(3):318-323.

42. Wright TM, Goharian I, Gardiner SK, Sehi M, Greenfield DS. Short-term enhancement of visual field sensitivity in glaucomatous eyes following surgical intraocular pressure reduction. Am J Ophthalmol. 2015;159(2):378-385.e1.

43. Caprioli J, de Leon JM, Azarbod P, et al. Trabeculectomy Can Improve Long-Term Visual Function in Glaucoma. Ophthalmology. 2016;123(1):117-128.

44. Heijl A, Bengtsson B. The effect of perimetric experience in patients with glaucoma. Arch Ophthalmol. 1996;114(1):19-22.

45. Wild JM, Searle A, Dengler-Harles M, O'Neill EC. Long-term follow-up of baseline learning and fatigue effects in the automated perimetry of glaucoma and ocular hypertensive patients. Acta Ophthalmol. $1991 ; 69(2): 210-216$.

46. Musch DC, Gillespie BW, Lichter PR, Niziol LM, Janz NK, Others. CIGTS Study Investigators Visual field progression in the Collaborative Initial Glaucoma Treatment Study the impact of treatment and other baseline factors. Ophthalmology. 2009;116(2):200-207.

47. Lucy KA, Wang B, Schuman JS, et al. Thick Prelaminar Tissue Decreases Lamina Cribrosa Visibility. Invest Ophthalmol Vis Sci. 2017;58(3):1751-1757.

48. Seo JH, Kim T-W, Weinreb RN. Lamina cribrosa depth in healthy eyes. Invest Ophthalmol Vis Sci. 2014;55(3):1241-1251.

49. Rhodes LA, Huisingh C, Johnstone J, et al. Variation of laminar depth in normal eyes with age and race. Invest Ophthalmol Vis Sci. 2014;55(12):8123-8133. 


\section{Tables}

Table 1

Table 1. Demographics and ocular characteristics

\begin{tabular}{|c|c|c|}
\hline Parameter & & Value \\
\hline age & Mean $\pm S D$ & $61.98 \pm 13.28$ \\
\hline \multirow[t]{2}{*}{ sex } & male & 44 (54.3\%) \\
\hline & female & 37 (45.7\%) \\
\hline \multirow[t]{2}{*}{ Baseline medications } & Mean $\pm S D$ & $3.14 \pm 0.85$ \\
\hline & Median (range) & $3(1$ to 4$)$ \\
\hline$C / D$ ratio & Mean $\pm S D$ & $0.81 \pm 0.15$ \\
\hline \multirow[t]{2}{*}{$A L$} & Mean $\pm S D$ & $23 \pm 1$ \\
\hline & Median (range) & 23 (20 to 25$)$ \\
\hline \multirow[t]{2}{*}{ CCT } & Mean $\pm S D$ & $539 \pm 32$ \\
\hline & Median (range) & 542 (432 to 632 ) \\
\hline \multirow[t]{2}{*}{$\mathrm{CH}$} & Mean $\pm S D$ & $11 \pm 2$ \\
\hline & Median (range) & 11 (6 to 14$)$ \\
\hline \multirow[t]{2}{*}{ CRF } & Mean $\pm S D$ & $10 \pm 1$ \\
\hline & Median (range) & 11 (7 to 14$)$ \\
\hline
\end{tabular}

AL: axial length, $C C T$ : central corneal thickness, $C / D$ ratio: cup-disk ratio, $\mathrm{CH}$ : corneal hysteresis, $\mathrm{CRF}$ : CRF. 
Table 2. Changes in study parameters after intervention

\begin{tabular}{|c|c|c|c|c|c|c|}
\hline & Pre & Post & & \multicolumn{2}{|c|}{$95 \% \mathrm{Cl}$} & \multirow[b]{2}{*}{$P$} \\
\hline & Mean \pm SD & Mean \pm SD & Diff & Lower & Upper & \\
\hline BCVA (logMAR) & $0.49 \pm 0.52$ & $0.55 \pm 0.53$ & -0.06 & -0.08 & -0.04 & $<0.001$ \\
\hline IOP (mmHg) & $22.77 \pm 5.14$ & $8.56 \pm 2.5$ & 14.2 & 13 & 15.4 & $<0.001$ \\
\hline $\mathrm{MD}(\mathrm{dB})$ & $-17 \pm 5$ & $-16 \pm 6$ & -1 & -1 & 0 & 0.23 \\
\hline LCT (microns) & $141 \pm 17$ & $142 \pm 18$ & -1 & -4 & 1 & 0.39 \\
\hline PLTT (microns) & $47 \pm 12$ & $52 \pm 12$ & 1 & 1 & 2 & $<0.001$ \\
\hline BMO (microns) & $486 \pm 57$ & $485 \pm 57$ & 3 & 2 & 5 & 0.234 \\
\hline ALD (microns) & $366 \pm 167$ & $324 \pm 165$ & 42 & 29 & 55 & $<0.001$ \\
\hline
\end{tabular}

BCVA: best corrected visual acuity, IOP: intraocular pressure, MD: mean deviation, LCT: lamina cribrosa thickness, PLTT: prelaminar tissue thickness, BMO: Bruch's membrane opening, ALD: anterior lamina cribrosa depth. 
Table 3

Table 3. Study variables difference between two groups with and without $3 \mathrm{~dB}$ MD improvement

\begin{tabular}{|c|c|c|c|c|c|c|c|}
\hline \multirow[b]{2}{*}{ Parameter } & \multirow[b]{2}{*}{ Time } & \multirow{2}{*}{$\begin{array}{c}\text { No MD } \\
\text { improvement } \\
\text { Mean } \pm \text { SD }\end{array}$} & \multirow{2}{*}{$\begin{array}{c}\text { MD } \\
\text { improvement } \\
\text { Mean } \pm \text { SD }\end{array}$} & \multirow[b]{2}{*}{ Diff } & \multicolumn{2}{|c|}{$95 \% \mathrm{Cl}$} & \multirow[b]{2}{*}{$\mathrm{P}$} \\
\hline & & & & & Lower & Upper & \\
\hline \multirow[t]{3}{*}{ BCVA logMAR) } & Pre & $0.52 \pm 0.56$ & $0.39 \pm 0.35$ & -0.13 & -0.42 & 0.16 & 0.375 \\
\hline & Post & $0.6 \pm 0.57$ & $0.45 \pm 0.34$ & -0.14 & -0.44 & 0.15 & 0.332 \\
\hline & Change & $0.07 \pm 0.1$ & $0.06 \pm 0.12$ & -0.01 & -0.07 & 0.05 & 0.805 \\
\hline \multirow[t]{2}{*}{$\mathrm{MD}(\mathrm{dB})$} & Pre & $-17 \pm 5$ & $-16 \pm 7$ & 1.01 & -1.9 & 3.93 & 0.491 \\
\hline & Post & $-17 \pm 5$ & $-12 \pm 7$ & 4.95 & 1.96 & 7.95 & 0.002 \\
\hline \multirow[t]{2}{*}{ IOP (mmHg) } & Pre & $21.88 \pm 4.9$ & $22.23 \pm 4.3$ & -1.35 & -6.9 & -1.71 & 0.542 \\
\hline & Post & $10.56 \pm 3.81$ & $9.82 \pm 1.5$ & 0.74 & -0.63 & 3.14 & 0.171 \\
\hline CCT (microns) & Pre & $541 \pm 34.1$ & $528 \pm 27.44$ & 13.26 & -4.7 & 31.22 & 0.146 \\
\hline AL (millimeters) & Pre & $22.97 \pm 0.99$ & $23.73 \pm 1.07$ & -0.75 & -1.131 & -0.2 & 0.008 \\
\hline $\mathrm{CH}$ & Pre & $10.6 \pm 1.59$ & $10.09 \pm 1.87$ & 0.5 & -0.4 & 1.4 & 0.27 \\
\hline \multirow[t]{2}{*}{ LCT (microns) } & Pre & $139 \pm 10$ & $137 \pm 11$ & -1.3 & -14.76 & 4.15 & 0.267 \\
\hline & Post & $142 \pm 19$ & $141 \pm 12$ & -1.07 & -10.21 & 8.82 & 0.885 \\
\hline \multirow[t]{2}{*}{ BMO (microns) } & Pre & $488 \pm 63$ & $471 \pm 34$ & -17.6 & -49.1 & 14 & 0.271 \\
\hline & Post & $485 \pm 63$ & $468 \pm 33$ & -17.1 & -48.6 & 14.4 & 0.284 \\
\hline \multirow[t]{3}{*}{ ALD (microns) } & Pre & $348 \pm 159$ & $463 \pm 176$ & 115.9 & 26.86 & 204.98 & 0.011 \\
\hline & Post & $324 \pm 168$ & $344 \pm 173$ & 19.4 & -73.24 & 112.08 & 0.677 \\
\hline & Change & $-23.2 \pm 37.6$ & $-119.7 \pm 60.0$ & -96.5 & -120.24 & -72.75 & $<0.001$ \\
\hline
\end{tabular}

BCVA: best corrected visual acuity, MD: mean deviation, IOP: intraocular pressure, CCT: central corneal thickness, AL: axial length, CH: corneal hysteresis, LCT: lamina cribrosa thickness, BMO: Bruch's membrane opening, ALD: anterior lamina cribrosa depth. 


\section{Figures}

Figure 1
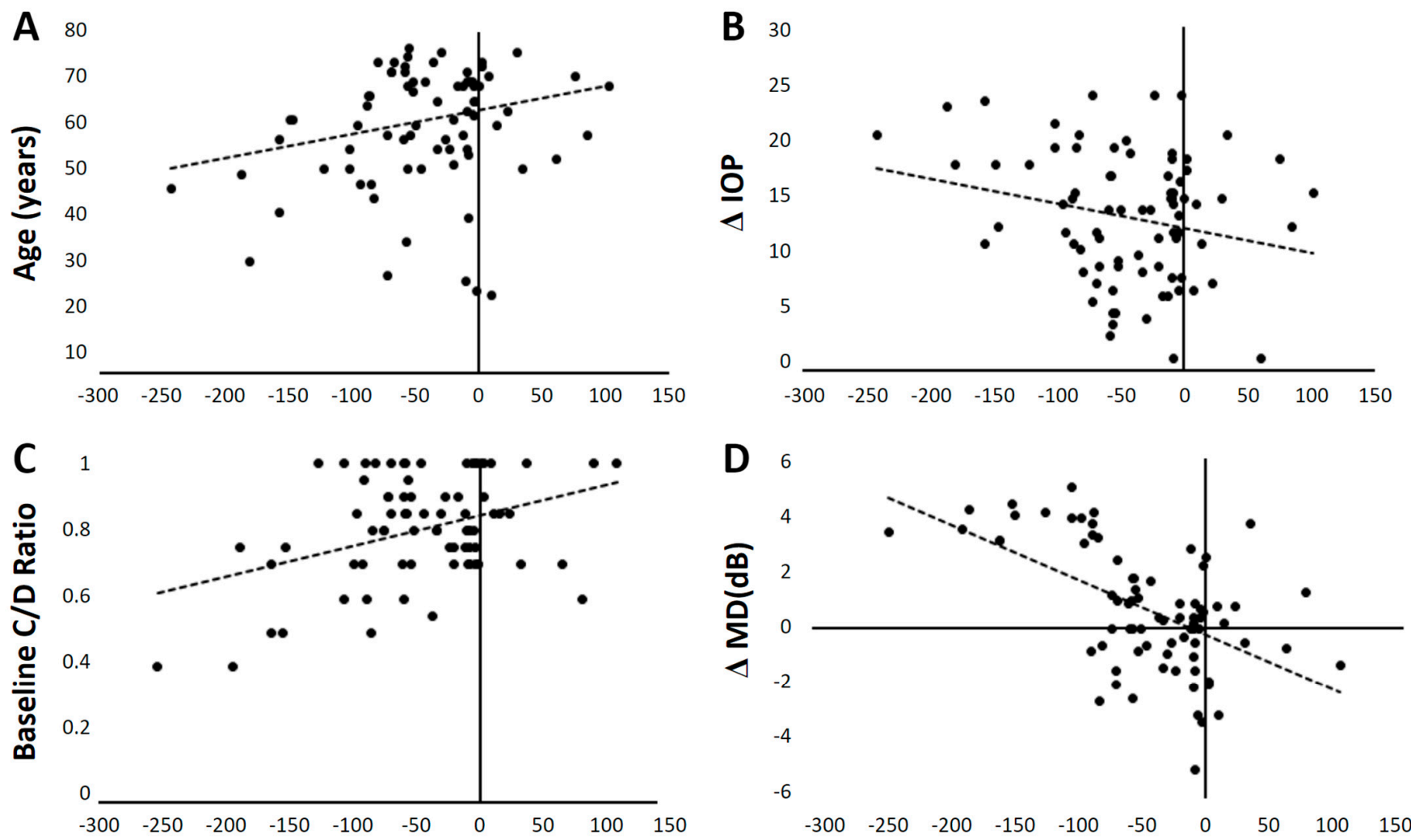

\section{ALDC (microns)}

Figure 1: Scatter plot and regression line of following outcomes: A) lamina cribrosa displacement (ALDC) resulted negatively correlated to age, regression coefficient: $-0.224, P=0.04$. B) ALDC was positively correlated with the amount of IOP reduction, regression coefficient: $0.251, P=0.02$. C) ALDC was large in eyes with lower baseline cup-disk (C/D) ratio, regression coefficient: $-0.212, P=0.05$. D) ALDC was positively associated with improvement in $\mathrm{MD}$, regression coefficient: $-0.18, \mathrm{P}=0.04$. 


\section{Figure 2}
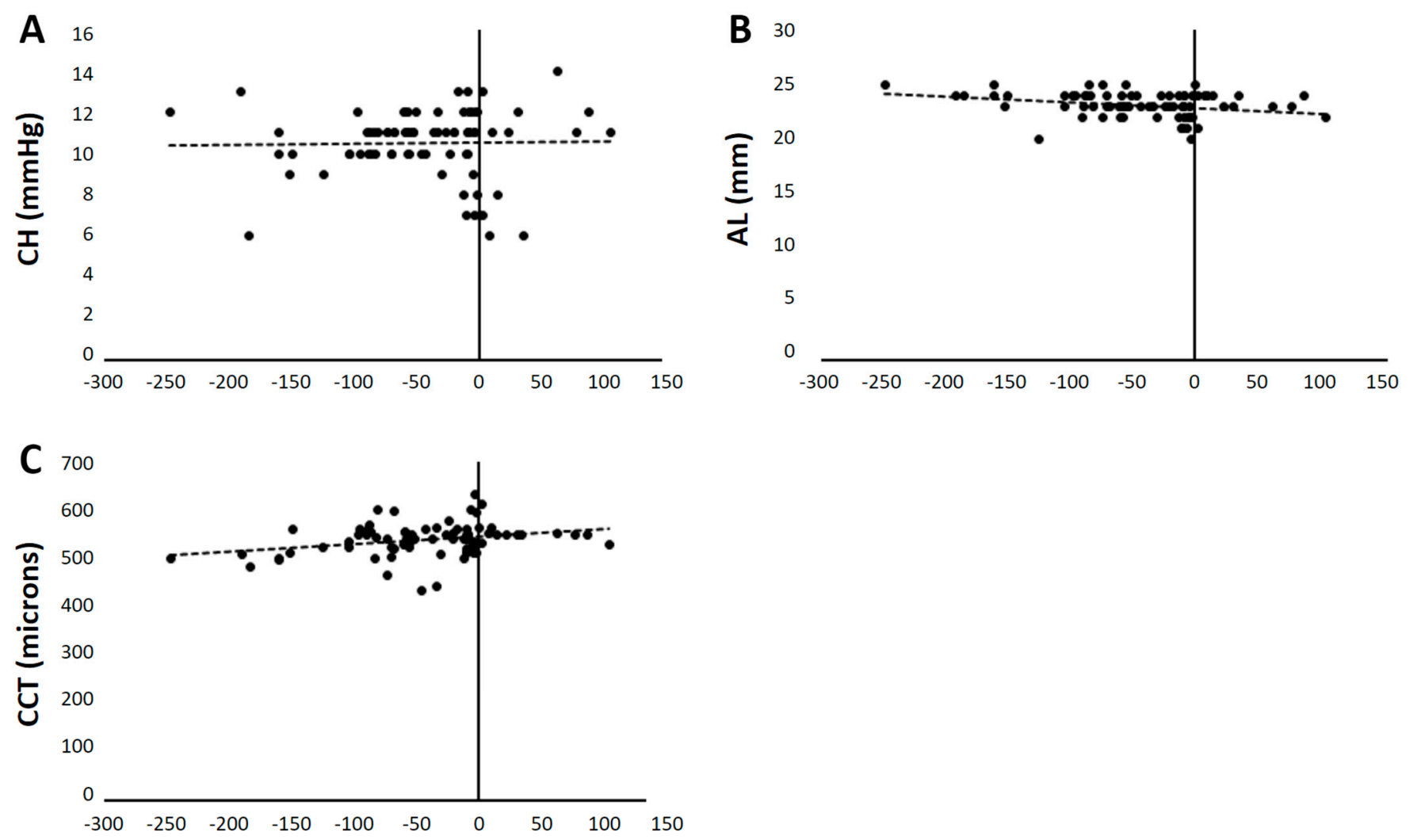

\section{ALDC (microns)}

Figure 2: Scatter plot and regression line of following outcomes $A$ ) there was no correlation between ALDC and corneal hysteresis $(\mathrm{CH})$, regression coefficient: $0.076, P=0.58$. B) ALDC was not associated with baseline axial length of the eye, regression coefficient: $-0.049, P=0.69$. C) there was no association between central corneal thickness (CCT) and ALDC, regression coefficient: 0.288, $P=0.09$. 